\title{
Completing The Dissertation: It's Not Only About Academics
}

Ramon Dominguez, (Email: radoming@nmsu.edu), New Mexico State University

\begin{abstract}
The culminating project in completing a doctorate in education is the preparation and final defense of the dissertation. Specifically in educational administration and leadership, the student will have exerted hours of energy participating in course work, internships as well as in written and oral comprehensive examinations.
\end{abstract}

By the time a student begins to prepare a dissertation proposal, hundreds of hours have been invested in academic endeavors. The student is well-versed in a variety of theoretical constructs that include leadership, organization, management, experimental design, statistics, law, finance, evaluation, and many other areas. The task remains to utilize the accumulated knowledge to successfully develop and complete the proposal and dissertation.

Academic knowledge is not sufficient to prepare the dissertation. A number of other factors must be included and considered in the development and successful completion of the dissertation. The formula for success includes both internal and external factors. The internal factors include goal setting, listening, writing strategy, benchmarking, confidence, flexibility, a positive disposition, discipline, adaptability, resiliency, humor, collaboration, and interpersonal skills. The external factors include time, family support, supervisor/institutional consideration, and advisor motivation.

\section{INTRODUCTION}

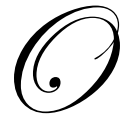

btaining the Ph.D. or Ed.D. in the American higher education system is one of the culminating achievements in academia. Students seeking this certification must complete a structured and complicated process that not only requires participation in prescribed coursework, internships and examinations, but must ultimately result in preparing and defending the dissertation. "Completion of the thesis/dissertation is a big hurdle in obtaining an advanced degree” (Pedron and Evans, 1992, p. 4).

Working through the dissertation process with the final goal of defending this essential document in front of a committee of university professors is a demanding experience that requires not only academic skill, but an understanding of a variety of internal and external factors that impact the completion of the document. Faculty and students embarking in the joint effort of developing and eventually presenting a dissertation would benefit by becoming aware and understanding the importance of these internal and external factors at the onset of their journey.

The factors presented in this discussion are not all inclusive and do not attempt to explain the reasons why students confront a temporary impasse and in many cases a permanent status in the "All But Dissertation" (ABD) category. However, an awareness of these internal and external factors prior to starting the dissertation can be beneficial. Specifically, faculty can assist students by conducting seminars or abbreviated courses that alert and essentially train students to maneuver through the complexity of the dissertation and the factors influencing the dissertation process. 


\section{LITERATURE REVIEW}

The literature describes a number of barriers impeding completion. Green (1997) discusses a number of internal variables that affect the completion process. High dependency needs, low levels of persistence, locus of control, inability to plan ahead, and, specifically, procrastination and perfectionism are considered by Green as barriers to progress. In a paper presented at the American Educational Research Association, Green and Kluever (1997), describe the administration of The Dissertation Barriers Scale to a sample of 142 graduates and 97 ABDs in an urban private college of education. The results identified time pressures as a major internal hindrance.

Hanson (1992), in a paper presented at the Speech Communication Association considers gender as an internal/external barrier. Hanson indicates that women are at a greater risk than men in successfully completing the dissertation and eventually completing an advanced degree. Additional internal barriers presented in Hanson's summary of other authors' research includes lack of focus, weak research topic, procrastination, inability to work independently, perfectionism, and lack of research sophistication. Myers (1999) identified time, frustration, and lack/loss of interest as factors impeding completion.

Myers (1999) further delineates external factors hindering completion. Approximately fifty-four percent of doctoral candidates in his study expressed difficulty with their advisor, a member of their committee or their entire committee. Burnett (1999) alludes to the importance of the dissertation supervisor's role in enhancing the dissertation process.

Other external barriers expressed by Myers (1999) included personal finances. Over seventy percent of students surveyed by Myers indicated personal finances were a contributing factor in not finishing the doctorate. Family/personal obligations and professional responsibilities were additional contributors. Hanson(1992), like Myers, identified job pressures, financial problems, family obligations, health problems, and distance from campus as impeding external barriers. Green and Kluever also list financial and family concerns as major external hindrances to the dissertation process.

\section{FACTORS}

Throughout the previous discussion, the internal and external factors have been identified as barriers to the successful completion of the dissertation. The brief review of literature clearly alludes to the impact these factors impose on student success. However, an attempt will be made in the remaining discussion of this paper to consider the manner in which internal and external factors can work in favor of the student. The basis of the discussion is not scientific, but mainly experiential. In essence, a set of recommendations will be presented in the utilization of these factors in creating a successful dissertation experience that culminates in the completion of the dissertation.

\section{INTERNAL FACTORS}

The internal factors documented in the literature review emphasize individual characteristics and their connection to failure or success in accomplishing the complex tasks involved in the preparation and completion of the dissertation. These documented internal factors provide insight to a similar set of individual characteristics that can influence success and diminish the prospect of an ABD permanent status. These success characteristics fall under three categories which include planning, personal disposition and communication.

Planning refers to the student's initiative to set goals, benchmark, and develop an efficient writing strategy. In moving toward a long-term goal, the development of a roadmap is key. The student needs to prepare a map outlining the goals and objectives of the dissertation project. The process involves determining the specific tasks to be completed within a specific timeline. A benchmark strategy drives the completion of each goal. For example, if a pilot study is to be conducted as part of the research, the student needs to commit to a defined set of timelines in conducting the pilot study. In many instances, students develop the plan as they move through the process hoping that things will automatically fall into place. The writing strategy component of the planning category also needs to be developed at the onset of the dissertation process. Just like goals, a writing strategy is set with long-term objectives. 
For example, the student should implement a writing plan that requires thirty minutes of writing, proof reading, and rewriting everyday. The task of writing, small but relevant sections at a time, becomes manageable. The project's overwhelming appearance is diminished.

The planning category has its foundation in the student's personal disposition. The enormous demands made on a student by the dissertation require a positive disposition. The student must work diligently to focus on the importance and meaning of the project. Frankl (1984) in his book, Man's Search for Meaning, speaks of the ability to choose one's attitude. The attitude is one which involves utilizing the hard work, endless hours of research, and the painstaking effort of writing as an incentive to complete the project. The attitude resonates with flexibility, discipline, confidence, and resiliency. Confidence and flexibility reflect on the ability to confront the unexpected. Discipline requires staying on task while at the same time smiling when obstacles tumble the best of plans. Most important in maintaining a positive disposition is bouncing back to the task after an unexpected circumstance. Resiliency overrides many obstacles.

The third category refers to communication. Strong interpersonal, collaborative, and listening skills assist in maintaining a grounded and focused direction in developing the dissertation. As the dissertation gains form, communication between student and advisor/committee is essential. The student needs to listen intently as well as express ideas, suggestions, and concerns. Sitting back and not communicating may have detrimental effects on the final product. A collaborative approach can assist in obtaining needed materials/information, carrying out the ideas and recommendations of the chair and committee, obtaining guidance from experts in the field of study, and setting the foundation for publishing an article based on the dissertation.

\section{EXTERNAL FACTORS}

Just as internal factors can positively impact the dissertation experience, external factors can have a similar influence. Advisor motivation, family support and supervisor/institutional considerations enhance the opportunities for completing the dissertation.

The Apprentice Master Model (Burnett, 1999) is the most current model utilized in preparing and developing doctoral dissertations. The model is the traditional method by which the doctoral student learns to conduct research by observing the master. This traditional approach emphasizes the importance of the dissertation supervisor (advisor) in the doctoral dissertation process. Therefore, the advisor is a key element in successfully guiding the doctoral student through the dissertation experience. The advisor can assist and motivate by taking genuine interest in understanding the academic and individual skills of the student. The advisor is in a position to advocate on behalf of the student with the doctoral committee, academic department and graduate school. Further, the advisor can guide the student in preparing as many rewrites as necessary without projecting a negative judgmental attitude. The feedback provided by the advisor is easily accepted by the student due to the realization that the advisor is focused on student success. With a strong working relationship between advisor and student, completing the final dissertation defense is an attainable goal.

Family support is another external factor that can have a positive influence on the doctoral candidate. With the family as a support system, the student feels less isolated and has a commitment and belief in a successful future (Frankl, 1984). Valverde and Rodriguez (2002) support the fact that due to isolation and lack of a strong committed network, students gravitate toward an ABD status. The family also instills light hearted moments into a demanding situation. When Dominguez (2004) interviewed students regarding the dynamics of group cohesiveness on preparing the dissertation, the impact of family was quickly expressed:

Friends and family have no clue what you are going through. Preparing a dissertation is nothing like other writing. It is a total different experience. Family, friends, and colleagues do not understand why the whole program and dissertation cannot be completed in a year.

When the support network includes the supervisor and institution, the doctoral candidate is in an excellent position to complete the dissertation project. When the supervisor realizes that an employee/student is in the final 
stage of a doctoral program and is willing to provide support, the doctoral student's motivation and emotional strength increase dramatically. The doctoral student can balance work and school responsibilities with less pressure and internal/external conflict.

\section{UTILIZATION OF FACTORS TO ASSIST STUDENTS}

Completing the dissertation is an engaging and tough experience that requires academic skill, stamina, persistence, and focus. A number of internal and external factors can contribute to a successful dissertation experience. Internal factors such as a positive disposition, resiliency, goal setting, and collaboration can complement external factors like family support, advisor motivation, and supervisor consideration in completing the final dissertation product.

Considering the positive impact these factors can contribute, educational administration preparation programs need to incorporate a training component into their curriculum that teaches the utilization of these and other factors. Faculty can provide training modules that emphasize interpersonal skills, resiliency, listening skills, and goal setting. Through receptions, presentations or video, faculty can reach family and supervisors to solicit their support and provide an awareness of the complexity of the dissertation process. Most importantly, faculty must mentor each other on techniques that successfully motivate, support, and empower doctoral students. A firm commitment from faculty to genuinely assist students and have their best interest in mind is an essential component in completing the dissertation.

\section{REFERENCES}

1. Burnett, Paul C (1999). The supervision of Doctoral Dissertations Using a Collaborative Cohort Model. Counselor Education and Supervision, 39, 46-52.

2. Dominguez, R. (2004, September). Group Motivation: Experiences of Doctoral Student in Distance Education Programs. Paper presented at the 2004 International College Teaching Methods and Styles Conference, Reno, Nevada.

3. Frankl, Viktor E. (1984). Man's Search for Meaning. New York, New York: Washington Square Press.

4. $\quad$ Green, K.E. \& Klueves, R.C. (1997). The Dissertation Barriers Scale. Paper presented at the Annual Meeting of the American Educational Research Association, Chicago, Il. (ERIC Document Reproduction Service No. ED 410 253).

5. Green, Kathy E. (1997). Psychosocial Factors Affecting Dissertation Completion. In L.F. Goodchild (Series Ed.), New Directions for Higher Education no. 99: Vol. 25. Rethinking the Dissertation Process: Tackling Personal and Institutional Obstacles (57-64). San Francisco, CA: Jossey-Bass Publishers.

6. Hanson, Trudy L. (1992). The ABD Phenomenon: The "at risk" Population in Higher Education and the Discipline of Communication. Paper presented at the Annual Meeting of the Speech Communication Association, Chicago, IL. (ERIC Document Reproduction Services No. ED 351 732).

7. Myers, L.H. (1999). Barriers to Completion of the Doctoral Degree in Educational Administration. Unpublished doctoral dissertation, Virginia Polytechnic Institute and State University.

8. Pedron, N.A. \& Evans, S.B. (1992). Research Survival Skills: Preparing a Master's Thesis, Field Project or Doctoral Dissertation. Paper presented at the Annual Convention of the Council for Exceptional Children, Baltimore, MD. (ERIC Document Reproduction Service No. ED 357-527).

9. Valverde, M. \& Rodriguez, R. (2002). Increasing Mexican-American Doctoral Degrees. The Role of Institutions of Higher Learning. Journal of Hispanic Higher Education, 1, 51-58 